\title{
Coupled natural and human systems: a landscape ecology perspective
}

\author{
Jiquan Chen · Yongqiang Liu
}

Received: 10 November 2014/ Accepted: 12 November 2014/Published online: 23 November 2014

(C) Springer Science+Business Media Dordrecht 2014

\section{CNHS and landscape ecology}

Coupled human and environmental systems, or coupled natural and human systems (CNHS), provide an integrated scientific framework for understanding the processes and complex interactions between natural and human systems (Turner et al. 2003; Marina et al. 2011; Wu 2013; Chen et al., in press). Natural systems are those such as biosphere, air, water, and soil that do not involve human factors. The structure, behaviors, and relationships among their internal components are governed by biological, physical, and environmental processes. The corresponding properties for human systems, on the other hand, are governed by social and economic processes (NSF 2008). The CNHS was first proposed 15 years ago and has emerged as a new frontier in both natural and social sciences, gaining great interest from various natural and social science

\section{J. Chen}

International Center for Ecology, Meteorology, and Environment (IceMe), Nanjing University of Information Science and Technology, Nanjing 210044, China

J. Chen $(\bowtie)$

CGCEO/Geography, Michigan State University,

East Lansing, MI 48823, USA

e-mail: jqchen@msu.edu

Y. Liu

Center for Forest Disturbance Sciences, USDA Forest

Service, Athens, GA 30602, USA

e-mail: yliu@fs.fed.us disciplines. The U.S. National Science Foundation initiated the Dynamics of Coupled Natural and Human Systems Program in 2007 (NSF 2008). The U.S. Regional Association of the International Association for Landscape Ecology organized "Complexity in Human-Nature Interactions across Landscapes" in 2009 in Snowbird, Utah, USA (Marina et al. 2011).

A primary driving force for the rapid advancement in CNHS research is the need to address the problem of deteriorating ecological and environmental conditions. The world has experienced increasing natural disasters, air and water pollution, water resource shortages, declines in critical habitats and biodiversity, and food and energy security problems in the past three decades, mainly as tradeoffs of the dramatic economic development and population increase in developing countries. Research for an individual natural or human system can reveal the changes and underlying processes related to the above challenges facing the scientific community and societies. However, the development of solutions depends on our understanding and the capacity for simulating and predicting the complex structures, variability, and interactions between the two types of systems.

Another important driving force is global change, which provides a platform with common issues for all natural and human science disciplines to assess the impacts and to develop adaptation and mitigation strategies. Furthermore, the natural and human systems will likely evolve more dynamically and become more complex under global change. Research on 
global change needs the joint efforts of natural and social scientists to provide scientific foundations and useful solutions. The CNHS is the core concept in the IPCC's climate change assessment reports and the Future Earth initiative. For example, the future carbon emission scenarios have been developed by considering not only industrial emissions but also technology progress and population-increase trends.

Landscape ecology aims to understand the interactions between ecosystems and their abiotic environments for individual landscapes by applying both biophysical and socioeconomic sciences (Wu 2006). Landscape ecology answers basic and applied research questions concerning the ecology, conservation, management, design/planning, and sustainability of landscapes. The unique feature of the close natural and human connections makes the CNHS an extremely valuable concept for landscape ecology research.

\section{About this Special Issue}

Many efforts have been made to understand these issues using the CNHS concept. With an overarching concept (Fig. 1), this Special Issue is developed to promote the CNHS study at the landscape level by publishing 11 research and review papers on these issues, as outlined below.
Ecosystem restoration

Ecosystem restoration is usually conducted through several stages including justification, planning, design, implement, and evaluation. Three studies investigate restoration at one or more stages. The dry forest landscapes in western North America, which once withstood burning, have become vulnerable to wildfires because of the long-time practice of fire suppression. Large fires, including mega-fires, have increased remarkably in the past two decades in this region and are projected to continue to increase in this century because of climate change. Thus, restoration of more fire-resistant and resilient forests is an important adaptation approach. Franklin and Hagmann (2014) provide their views on this issue and describe the societal goals, barriers, and approaches during the restoration. Two other studies investigate ongoing restorations in China. Hao et al. (2014) focus on the roles of climate conditions. The ecological effects of grassland grazing exclusion are evaluated using long-term field measurements in northern China. The grazing exclusion effectiveness is found to vary spatially across the region, depending mainly on moist conditions. They suggest the importance to select an area with appropriate climate conditions for grassland restoration. Liu et al. (2014) focus on the carbon sequestration of restoration. The magnitude and
Fig. 1 A framework in landscape studies based on CNHS concept

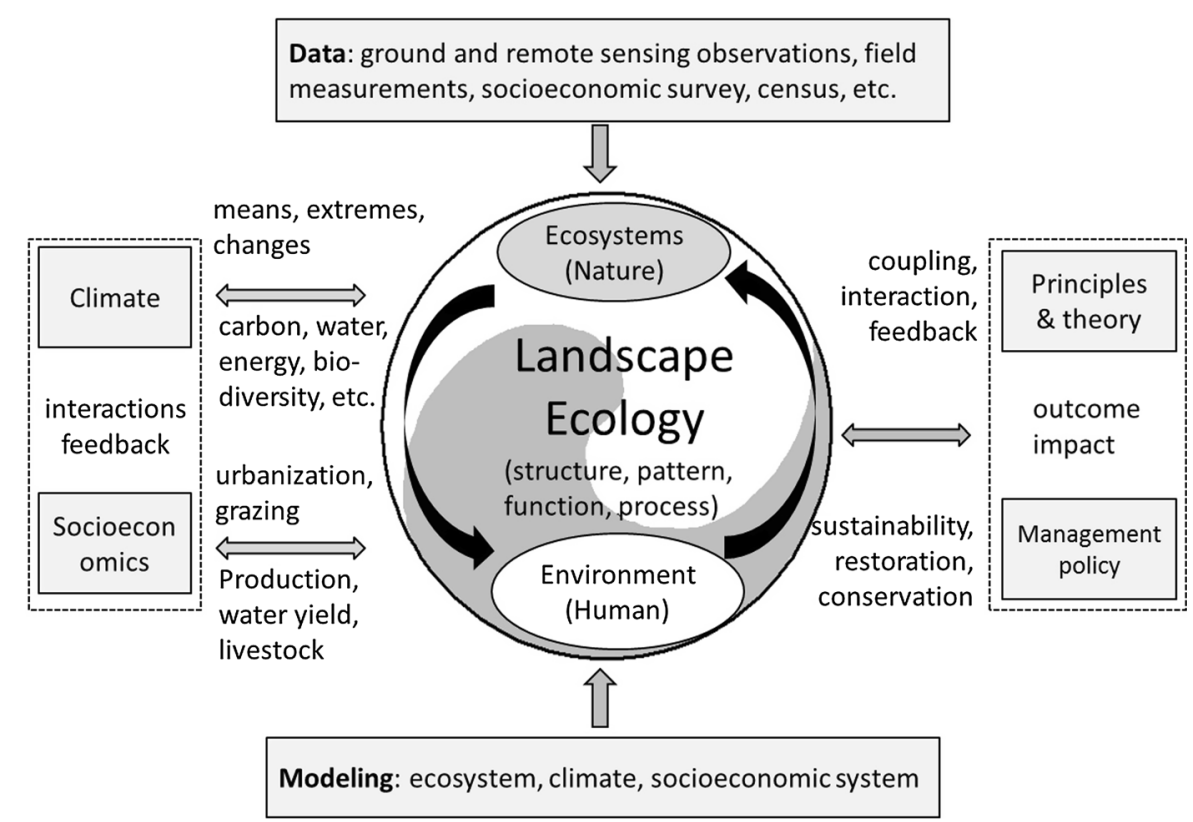


spatial variability of current and future carbon sequestration are simulated using a process-based ecosystem model. They find significant contribution of the cropto-forest conversion to reduce atmospheric carbon and the contribution would become greater while the program continues in the future.

\section{Ecosystem services}

One concern in understanding ecosystem services is that the prevailing approach to quantify ecosystem services is still based on static analyses and single services, ignoring system dynamics, uncertainty, and feedback (MEA 2005; Nicholson et al. 2009). This concern is addressed in two studies. Zheng et al. (2014) focus on the relationships between ecosystem services and driving factors and their dynamic changes over time. The important role of land cover change due to crop-to-forest conversion in modifying the outcomes of the ecosystem services is investigated. $\mathrm{Lu}$ et al. (2014) focus on the interactions of different ecosystem services in a water-limited landscape. Trade-offs along a precipitation gradient are found to be the highest between understory plant diversity and soil water content and the lowest between soil organic carbon and soil total nitrogen. Considering the high variations with ecosystem services and their trade-offs across the landscape, spatially explicit management is needed for the best possible ecosystem service outcomes.

\section{Urbanization}

Comparisons of urban CNHS interactions at various periods are essential to understand the dynamic processes during urbanization. Four studies adopt this concept to investigate specific problems on the relationships between urban ecosystems and their environments. Fan et al. (2014) examine the vulnerability of the urban CNHS using long-term data for Lanzhou, China, with rapid expansion in size and population but degraded ecological and environment conditions. Geophysical factors, economic regimes, and institutional factors are identified as crucial contributors. Liang and Liu (2014) look into how an urban area in a countryside-dominated region grows in response to different scenarios of development. The SLEUTH model is calibrated and validated with remotely sensed historical records and strategic planning data for 4 years over a span of 15 years. The simulated urban growth is very different with respect to varied levels of managed growth limitations and environmental protection. Ren et al. (2014) investigate the mechanism through which urbanization, human activity, and ecological factors affect the connectivity of an urban forest landscape. A combined approach of graph theory and geographical detector model is used. Climate is found to be more important than population in controlling the spatial pattern of connectivity. The connectivity is enhanced by the interaction between population and ecological properties. Wang et al. (2014) examine the causes for unsuccessful artificial greenbelt development. The past land use/land cover is determined using aerial photographs for Shanghai. Their roles, together with those of population movement and current socioeconomic factors are examined.

\section{Fuel treatment}

While an ecosystem management activity generally benefits society, it could produce adverse byproducts. Two studies address this issue by examining controlled burning. Forest fuel type and load have a much more complex spatial structure in wildland-urban interfaces (WUIs) than that in rural areas where fire can move easily from forests to human settlements in a WUI. Because of limited work power and finance, it is critical for mangers to determine where and what type of forest areas may be eligible for fuel removal in a WUI. Elia et al. (2014) provide an index to help managers make a decision, which considers both fuel and social information (e.g., population density, urban density and road density) and represents combined natural and human conditions. Shi et al. (2014) provide a review on agricultural burning in China and the related environmental, ecological, and economic influences. To improve the degrading air quality, China recently issued new regulations to limit or ban agricultural burns, which can emit large amounts of air pollutants such as particulate matters and ozone precursors. Scientific evidence is provided for this action based on an assessment of the contributions to haze and smog events from agricultural burning. The need is emphasized for the government and managers to provide effective alternatives for farmers to remove agricultural residues in the wake of the regulations. 
It is expected that the studies presented in this Special Issue will improve our understanding of the landscape ecology CNHS. A framework for the landscape ecology CNHS can be formed based on these studies. Each of these studies is connected to this framework as one or more components of the coupled system.

Acknowledgments This Special Issue derives from a symposium on "Global Change Research 2013-Coupled Natural and Human Systems" held in Nanjing, China in June, 2013, sponsored by the IceMe of NUIST. We wish to express our thanks to Dr. Jingle Wu for supporting this Special Issue and providing guidance throughout the review process.

\section{References}

Chen J, John R, Zhang Y, Shao C, Brown DG, Batkhishig O, Amarjargal A, Ouyang Z, Dong G, Wang D, Qi J (2015) Divergences of two coupled human and natural systems on the Mongolia Plateau. Bioscience (in press)

Elia M, Lafortezza R, Colangelo G, Sanesi G (2014) A streamlined approach for spatial allocation of fuel removals in wildland-urban interface. Landscape Ecol 1-14 (this issue)

Fan P, Xie Y, Qi J, Chen J, Huang H (2014) Vulnerability of a coupled natural and human system in a changing environment: dynamics of Lanzhou's urban landscape. Landscape Ecol 1-15 (this issue)

Franklin JF, Hagmann RK (2014) Integrating societal goals into restoration of dry forest landscapes in western North America. Landscape Ecol (this issue)

Hao L, Sun G, Liu YQ, Gao Z, He J, Shi T, Wu B (2014) Effects of precipitation on grassland ecosystem restoration under grazing exclusion in Inner Mongolia China. Landscape Ecol (this issue)

Liang Y, Liu L (2014) Modelling urban growth in the middle basin of the Heihe river, northwest China. Landscape Ecol (this issue)

Liu D, Chen Y, Cai W, Dong W, Xiao J, Chen J, Zhang H, Xia J, Yuan W (2014) The contribution of China's Grain for Green Program to carbon sequestration. Landscape Ecol 1-14 (this issue)

Lu N, Fu B, Jin T, Chang R (2014) Trade-off analyses of multiple ecosystem services by plantations along a precipitation gradient across Loess Plateau landscapes. Landscape Ecol (this issue)

Marina A, Asbjornsen H, Alberti M, Bake LA, Brozovic N, Drinkwater LE, Drzyzga SA, Jantz, Fragoso CAJ, Holland DS, Kohler TA, Liu J, McConnell WJ, Maschner HDG, Millington JDA, Monticino M, Podestá G, Pontius RG, Redman CL, Reo NJ, Sailor D, Urquhart G (2011) Research on coupled human and natural systems (CHANS): approach, challenges, and strategies. Bull Ecol Soc Am 92:218-228

Millennium Ecosystem Assessment (MEA) (2005) Ecosystems and human well-being: synthesis. Island Press, Washington

Nicholson E, Macel GM, Armsworth PR, Atkinson G, Buckle S, Clements T, Ewers RM, Fa JE, Gardner TA, Gibbons J, Grenyer R, Metcalfe R, Mourato S, Muûls M, Osborn D, Reuman DC, Watson CC, Milner-Gulland EJ (2009) Priority research areas for ecosystem services in a changing world. J Appl Ecol 46:1139-1144

National Science Foundation (NSF) (2008) Dynamics of coupled natural and human systems $(\mathrm{CNH})$ program solicitation NSF 07-598. http://www.nsf.gov/funding/pgm summ.jsp?pims_id=13681. Accessed 1 Nov 2014

Ren Y, Zuo S, Luo Y, Wei X, Yan J, Yang Y (2014) Interaction between human activity and urban forest landscape connectivity: combining graph theory and geographical detector model. Landscape Ecol (this issue)

Shi T, Liu YQ, Zhang L, Hao L, Gao Z (2014) Burning in agricultural landscapes: an emerging natural and human issue in China. Landscape Ecol (this issue)

Turner BL, Kasperson RE, Matson PA, McCarthy JJ, Corell RW, Christensen L, Eckley N, Kasperson JX, Luers A, Martello ML, Polsky C, Pulsipher A, Schiller A (2003) Science and technology for sustainable development special feature: a framework for vulnerability analysis in sustainability science. Proc Natl Acad Sci 100:8074-8079

Wang HB, Li H, Ming HB, Chen JK, Zhao B (2014) How past land use/land cover decisions and socioeconomic factors influence artificial greenbelt development in Shanghai, China. Landscape Ecol (this issue)

Wu J (2006) Cross-disciplinarity, landscape ecology, and sustainability science. Landscape Ecol 21:1-4

Wu J (2013) Landscape sustainability science: ecosystem services and human well-being in changing landscapes. Landscape Ecol 28:999-1023

Zheng Z, Fu B, Hu H, Sun G (2014) A way to identify the variable ecosystem services relationship across time: a case study on Yanhe basin, China. Landscape Ecol (this issue) 